\title{
The Relationship of Some Immediate Chemo-Chemical Variables after the Aerobic Physical Increasing Effort for Football Players
}

\author{
Hatem Abdulkareem Mohammed ${ }^{1}$, Firas Abdulhameed Khalid ${ }^{2}$ \\ ${ }^{1}$ The General Directorate of Education in Anbar Province/The Open Educational College/Department of Physical \\ Education and Sports Sciences, ${ }^{2}$ The General Directorate of Education in Anbar Province/The Open Educational \\ College/Department of Physical Education and Sports Sciences
}

\begin{abstract}
In order to study some biochemical variables on the increasing aerobic physical stress-test, the researchers selected a sample of individuals represented by the Anbar University football team of 16 players who underwent this study. The researchers used the descriptive approach in their research. The research experiment included taking blood samples before and after the escalating physical exertion on the Treadmill device in order to know the effect of this effort on some biochemical variables (cholesterol, white blood cells, lactic acid). They conducted aerobic increasing physical effort stress-test on a Treadmill device which has an impact on the targeted Chemo-chemical variables and the existence of correlative relationships between those variables. The researchers concluded that there are significant changes in these variables in favor of the post-test measurements, as well as obtaining significant correlation coefficients between these three biochemical variables. Then the researchers recommended the necessity of conducting studies in the same regard to the rest of the other difference games and the need to study other variables and recognize the correlations between those variables. To design curricula Modern training according to scientific foundations to enhance the positive correlation between the variables that were discussed and reduce the relative difference between the variables whose relations have gone in the negative direction and that negatively affects the physical achievement.
\end{abstract}

Keywords: Chemo-Chemical Variables, Aerobic Physical.

\section{Introduction}

In recent years, the world has seen considerable progress in various fields. Physical education has had a significant share of that progress, as demonstrated by the results, achievements, and record subjects of various sports and events, both individual and team, It is through continuous research and proper recruitment, and the aim of that research for the service of achievement and its upgrading. The training process is a difficult and complex process that needs a lot of data and information

\section{Corresponding Author:}

\section{Firas Abdulhameed Khalid}

The General Directorate of Education in Anbar

Province/The Open Educational College/Department of Physical Education and Sports Sciences

e-mail: firassport666@anbaredu.org from the game to give the trainer a clear picture of that player, which in turn will make it easier for the trainer to develop appropriate training curricula that are compatible with the capabilities and capabilities of each player. The blood variables from the internal variables that are to be studied deeply reflect a clear picture of the inner environment of the player's body during and after the performance because "blood forms the inner perimeter of the body"[1]. The concentration or level of these variables is directly related to performance, as the rise of some of them supports performance and increases its quality, while the reduction of some of them negatively affects performance As a result, there are many changes in their work, such as the respiratory system, the heart, and the circulatory system, the nervous system, the neuro system, the hormonal, enzymological system and other devices Internal to the training load on the player and in a way that serves performance and achievement. 
This is why a football player is exposed to the fatigue that can occur because of these chemical changes in the internal environment of the body, which may affect negatively on his physical, professional, plan, and psychological performance, which has led us to research of some of his body Biochemical changes caused by increased physical activity and the study of the quality of relational relationships between these variables.

It is important to study the current changes in some blood variables due to an increasing aerobic physical effort and therefore to know the relationships between these variables, which in turn gives us a clear picture of the nature of these changes and how they affect the level of performance of the player, whether negative or positive, especially given that knowledge The nature of relational relationships between these variables will allow the trainer to reinforce the positive and minimize the negative results.

The research problem was the effectiveness of football match that requires a major physical effort that lasts for (90min), The problem of research is the need to know and study these changes and to know the nature and level of these changes by the coach and even by players andtheir effects on performance, especially blood variables which plays an important role to player's performance during the match.

\section{Method and Procedures}

The researchers used the Descriptive study, which studies of some blood variables and their impact on an increased physical effort and the relational relationships between those variables. Theaims of the research were:

1. Recognize the impact of increased physical effort on some blood Chemo- chemical variables (white blood cells, lactic acid, and cholesterol).

2. Identify the level of the relational relationship between the Chemo-chemical variables under study.

The sample of the research was 16 players of $\mathrm{Al}$ Anbar University participate in the reconnaissance experiment. TheExperiment location was the main stadium of Al Anbar University and the Faculty of Science laboratories in the university.And the temporal domain was $(5 / 9 / 2018$ to $26 / 9 / 2018)$. The Research means and tools were used the TREDEME 4 of the same type and origin and special blood-preservation tubes containing anticoagrotic, medical injection, and gauze. Survey experience Research procedure the researcher uses to organize and arrange his field research work, identify obstacles and problems that may arise for the researcher when initiating his main experience, distribute tasks and roles for the assistant staff, identify their capabilities and capabilities to carry out their assigned tasks and ensure the safety of the equipment and tools used in the research.

The assistant staff performed the pre-test measurements of the Chemo-chemical variables on the sample members for research, as these variables were measured by the changes of white blood cells, lactic acid, and cholesterol at 4:00 p.m. on Thursday, 09/13/2018in Al Anbar University, where blood samples are taken from the sample individuals, and by a quantity of $(5 \mathrm{ccs})$. The test is a very good way to get the test to be used, and the test is a good way to get the test done another influential is the physical practice or any physical effort.

The assistant staff conducted the Tread-Mill physical Stress-Test upon completion of the blood sample sampling of the research samples and represented the test with the physical Stress-Test. The procedure for this test is as follows:

The player sample warmed up for (10 minutes) on the device by walking on the Tread-Mill with speed (3.5 hours/miles) and with inclination angel $(0 \%)$ and after the warm-up, the testingbegins on the Tread-Mill, as the player runs on the device with speed 7 hours/miles ( 2 minutes), inclination $(0 \%)$, and after two minutes, theinclination increases to (2.5\%) after every( 2 minutes) until the end of the test, and it is known that the test time is (12 minutes) continuous and continuous without any interruption $^{[2]}$.

The assistant staff performed the following measurements of the research sample blood-bloodblood variants by venous blood draw from the sample, and by the fact that two blood clouds were immediately upon the sample descent from the device and by (5 cc) to measure the changes of white blood pellets and cholesterol and the second five minutes after they have completed an upward physical effort as post-test $(5 \mathrm{cc})$ also, to measure lactic acid variant after withdrawal, blood samples were placed in special blood-preservation tubes prepared for this implantation, transferred to the laboratory and analyzed to see all changes due to the increased physical effort.

Because of this research method, the researchers developed the following research questions: 
1. Is an increasing physical effort having clear and significant effects on blood Chemo-chemical Variables?

2. Are there any relationships between the blood Chemo-chemical variables after increased physical effort?

\section{Results}

The following measurement of the biochemical variables in blood was handled between the pre and post results with used the SPSS Statistical Package. It was presented by researchers in the following tables ( 1 and 2 ), and they were provided with analyzes and attached, strengthened by scientific sources and references.

Table (1): Mean, standard deviations,Mean difference, standard deviations of differences, and the calculated (T-test) value to measure the white blood cell variables, Lactic acid, and cholesterol

\begin{tabular}{|c|c|c|c|c|c|c|c|c|c|}
\hline \multirow{3}{*}{\begin{tabular}{|l|}
$\begin{array}{l}\text { Statistical } \\
\text { parameters }\end{array}$ \\
Variables \\
\end{tabular}} & \multirow{3}{*}{ Measuring unit } & \multicolumn{2}{|c|}{ Pre-test } & \multicolumn{2}{|c|}{ Post-test } & \multirow{3}{*}{ MD. } & \multirow{3}{*}{ SD. } & \multirow{3}{*}{$\begin{array}{c}\text { Calculated } \\
\text { value }(T)\end{array}$} & \multirow{3}{*}{$\begin{array}{c}\text { Level of } \\
\text { Significance }\end{array}$} \\
\hline & & \multirow{2}{*}{ M } & \multirow{2}{*}{ S.D } & \multirow{2}{*}{$\mathbf{M}$} & \multirow{2}{*}{ S.D } & & & & \\
\hline & & & & & & & & & \\
\hline White blood cells & Cell/mL 3 & 5914.55 & 625.43 & 8225.13 & 852.11 & 2615.78 & 727.18 & 10.16 & Sig. \\
\hline Lactic acid & $\mathrm{Mg} / 100$ milliliters & 10,2 & 0.461 & 22,7 & 0.366 & 43,1 & 465,0 & 254,19 & Sig. \\
\hline Cholesterol & $\mathrm{Mg} / 100 \mathrm{ml}$ & 185.33 & 18.19 & 198.34 & 23.06 & 17.22 & 11.19 & 4.45 & Sig. \\
\hline
\end{tabular}

The tabulated T-value (2.947) at the degree of freedom (16-1=15) and the level of Significance (0.01), Relative confidence $99 \%$.

\section{Discussions}

We find out from Table(1), which includes the statistical parameters, that there are differences between the post and pretest results of the variables, and for the benefit of the post-tests. The researchers attribute these differences to the increased physical effort of the sample research, which has had a direct impact on the target Chemo-chemical variables, and it is known that a physical effort with an inclinationwould increase the alert status of the body's internal environment and all its organs and clearest, making it work faster, stronger, and more to confront the requirements of that work.

The increase in the rate of blood pressure in the arteries and the roses that pass through them affects blood components in general and blood cells, the white blood is especially so as indicate that there are a large number of white blood cells that are adjacent to the walls of blood vessels that the blood passes through during the rest time, and these pellets are pushed with blood when performing a physical effort, as these cells are left on the walls of blood vessels to get into the bloodstream ${ }^{[3]}$. The higher the level of physical effort increases the number of white cells. The longer and more physical effort, the more white blood cells, and this view are reached after a series of research, concluding that these white cells have increased their number by a certain percentage after a runaway race (200) meters this percentage of white cells increased further after the race at two (800) meter runners and the increase was significantly higher, but this increase was more apparent after the previous (1500) meters ${ }^{[3]}$. Which indicates that exercise and athletic performance of physical efforts increase blood components in general as both red and white blood cells and hemoglobin increase in size due to the exigencies of performing physical work ${ }^{[4]}$.

The researchers attributed the differences in lactic acid variant between the pre and post-tests that were in favor of the post-test to the fact that the increased physical effort means the difficulty and severity of the sample during the performance was the increasing degree of the device's inclination after every two minutes, which makes it difficult. The intensity gradually increases as the performance progresses and this increasing continuously elevate heart pulses, making more effort on the player gradually increase, and it is known that increasing performance leads to more metabolic processes and energy release to match that intensity and work requirements, causing the formation of metabolic residues, including acid The lactic action is one of the most important causes of fatigue. A physical effort of maximum or lesser intensity increases the amount of lactic acid that causes muscle fatigue and this acid gradually increases the performance intensity, i.e. the higher the performance the acid build-up. Studies 
have suggested that lactic acid not only increased muscle to non-oxygenated exercises or efforts but also even in oxygen training and efforts, it appears because of adrenaline hormone but less ${ }^{[5]}$.

We explain the results of the differences between the pre and post-tests of the cholesterol variant that was in favor of the post-test, to the direct effect of the increased physical effort on the sample, as this step-by-step effort by increasing the device's inclination degree after every two minutes increased the frequency of metabolic operations. The increased need for energy production is the result of the muscular work produced during this effort, resulting in the accumulation of many unfinished substances in the blood after the severe physical effort, which is part of the substances. The period immediately following "intense work performance" is the blood on non-combustion substances such as lactate acid, pesticides, and ketones. All of these materials are burned when oxygen is taken in the break-in period following intense work." ${ }^{[6]}$.

The exercise of physical activity would provoke the body's hormone system, which would make it responsive and work to create a state of internal balance. This makes it increase during the performance period and it is known that increasing the proportion of this hormone in the blood directly affects the percentage of fatty acids, which makes them increase further and which can be used as a source of energy ${ }^{[1]}$. The growth hormone is more susceptible to increase as physical activity increases, its importance appears to be in its ability to metabolize and consume fat as a source of energy, and it also plays an active role in metabolizing fatty acids and converting them from fatty tissue to the bloodstream when exercising physical efforts for a long time ${ }^{[1]}$.It is known that physical effort, such as physical effort, in the sample of research, makes it necessary for the body to release the energy needed to continue working and as a result of long effort (length of the physical effort performed). The energy sources used and from these sources are many fatty acids. The cells can benefit from the release of energy by continuing physical activity and, of course, that these acids need a source to be transported to those cells and cholesterol is one of the most important carriers of these acids during periods of physical work. The main activity of cholesterol is its ability to form an ester and then its ability to act as a transfer of fatty acids in the body, which are sources of energy the body uses when it is needed ${ }^{[7]}$. Thus achieving the first assumption of research.
Table (2): Shows the values of multiple correlation relationships between Chemo-chemical variables

\begin{tabular}{|l|l|l|}
\hline Variables (A) & White blood cells & Cholesterol \\
\cline { 1 - 2 } Variables (B) & Lactic acid & \multicolumn{2}{|c|}{0.601} \\
\hline
\end{tabular}

The tabulated Person-value $(0,497)$ at the degree of freedom $(16-2=14)$ and the level of Significance (0.05), Relative confidence $95 \%$.

\section{Discussions}

The table above shows the statistical multiple correlation values that show the relationship between the research variables, white blood cells, lactic acid, and cholesterol. The multiple correlation values between the 3 Variables $(0.601)$ is significant, and therelative confidence $95 \%$. The researchers attribute that tothe physical effort of subjects has caused a state of alert in the internal environment of the body, which is, of course, a result of the degree of performance or work due to the increased of the deviceinclination, which has made it more difficult to work requirements and has led to a cardiac arousing and blood pumping circuit for the common muscles in the work to continue In energy liberalization, this has made the circulatory system and heartbeats increase its frequency. Which directly affected the number of white cells and made them go out in more numbers than their natural numbers and go into the brain stream. The topic of the effects of training on white blood cells and the quality of training related to the type of cells that increase the number of shortrange anaerobic training increases the number of lymph white blood cells (Lymphocyte), long-term aerobic training affects the equivalent white blood cells (nitro Ville), which make up a large proportion of the total number of white blood cells, reaching approximately $60 \%-70 \%$ of the total number of cells and appears and their added value in being the first line of defense ${ }^{[8]}$. The increased exposure of the research sample to the increased intensity of the search also increased the of lactic acid concentration that caused a rise in an acidic grade of the center or the internal environment (blood) due to the hydrogen ions that are free from lactic acid and which in turn reduced the $\mathrm{pH}$ value. The longer the exercise lasts, the more time the production of lactic acid [9], increases and the increase in the central acid caused by the decrease in phages, confirmed by ${ }^{[10]}$, The increase in lactic acid in the blood is seen as contributing to the reduction of $\mathrm{pH}^{[11]}$. 
From the above, it becomes clear to us that the relationship between the increased physical effort and white blood cells is a significant correlation, so with the increase in the physicalincreased effort the level of these blood cells rises, as well as the relationship between the physical effort and lactic acid as well as a positive relationship, its increases the level of lactic acid and this increase is caused by the increase in the frequency of oxidation processes as a result of the physical load to which the research sample was exposed, so by increasing the level of oxidation processes (the oxidative) that accompanies the implementation of the physical load, the level of each level of both lactic acid and white blood cells rises, and this is confirmed by James, Bosch,and Aldred. As this research team found through a field study conducted at the College of Medical Sciences and Dentistry at the University of Birmingham in Britain that the practice of strong physical exercises would increase the oxidative stress in the internal tissues and blood, which leads to a high level of white cells and that this rise is caused by the high level of the adrenaline hormone, which increases with the progress of the effort, which in turn reduces the adhesion of white cells on the one hand and increases their release from the lining the blood vessels in which the blood passes, and some of its stores in the spleen and lungs, on the other hand ${ }^{[11]}$.

Aqeel believes that the increase in the level of physical load would increase the level of concentration of growth hormone and that increasing this hormone increases the concentration of fatty acids in the blood ${ }^{[12]}$, and that this increase in the level of fatty acids contributes directly to the increase in the level of cholesterol, which is the main carrier of these acids as indicated previously, which he refers to Fadel, in that he has an important role during the exercise of physical exertion and exercise. He pointed out that all fats, with all their varieties and types, which exist in different proportions in the human body, including cholesterol, play an important and major role in supplying the body with the energy needed when needed, especially for the practice of continuous and relatively long physical loadand this is what It makes us conclude that the correlation between each of the physical exacerbations and the intensity of cholesterol is a direct relationship, so with increasing load intensity or performance, the concentration of cholesterol increases. If we address the level of the relationship between physical exacerbation and intensity of lactic acid, we find that the increased demand for the body's need for more energy to continue working as a result of the exacerbated physical exertion led to an increase in the speed of metabolic processes that produce lactic acid.

The increase in the intensity of performance contributes to the increase in metabolic activity, which in turn leads to the accumulation of lactic acid as a byproduct of this activity ${ }^{[13]}$.

We conclude that a positive relationship between physical stress and increasing intensity and cholesterol is a direct relationship. The increase in the level of physical effort with increasing intensity is offset by an increase in the concentration of cholesterol, as it becomes clear to us that the correlation between the physicalincreasedeffort and lactic acid is also a positive relationship, that is, the increase in physical load work. It is accompanied by an increase in the concentration of lactic acid and this leads us to say that the correlation between both cholesterol and lactic acid is a positive relationship and this is confirmed by ${ }^{[14]}$, as they see that the physical effort contributes to increasing the outputs of the metabolic processes that are represented by the production of fatty acids as a result of lipolysis as well The production of lactic acid that releases hydrogen ions that cause the $\mathrm{pH}$ value to drop ${ }^{[14]}$.

\section{Conclusion}

Based on the discussions discussed in Tables 1 and 2 on the results of Chemo-chemical tests before and after the increasing effort stress-test of the football players sample, we came to summarize the conclusions as follows:

- We conclude that the aerobic increased Physical stress-test on the treadmill device significantly affects the Chemo-chemical variables of blood, such as white blood cells (leukocytes), cholesterol, and lactic acid. Thus, the assumption of the first research question was answered.

- We conclude that the three Chemo-chemical research variables have significant internal multiple correlations, which are white blood cells (leukocytes), cholesterol, and lactic acid. With this result, we were able to answer the second research question.

\section{Recommendations:}

- An increasing physical effort having clear and significant effects on blood Chemo-chemical Variables such as white blood cells (leukocytes), 
cholesterol, and lactic acid, therefore, these results should be taken into account well in training programs for various sports and endurance activities in particular.

- The relationships between the blood Chemochemical variables after aerobic increased physical effort stress-test, those results should be paid attention to studying other variables of the circulatory system and blood because of its importance in the general health of athletes in general and the effects of training units in particular.

Acknowledgment: The researcher's thanks tothe Iraqi education Ministry and Anbar University stadium and the science college's laboratories, and a football teamfor the facilities provided to the researchers.

Ethical Clearance: This article does not contain any studies with human participants or animals performed by any of the authors.

Source of Funding: Self-funded by the authors.

The Conflict of Interest Statement: All authors have no conflicts of interest.

\section{References}

1. Abdel-Hamid A. Encyclopedia of Physiology of Throwing Competitions. Cairo: The Book Publishing Center; 2001. 289 p.

2. Hassan Faleh A. The effect of two training curricula in the high-intensity hypothetical and hypoxic conditions in developing some physical characteristics, basic skills, and biochemical and functional variables for young football player [Ph.D. thesis]. College of Physical Education, Basra University; 2009.109 p.

3. El-Din B, Salama I. Physiology of Sport and Physical Performance (Blood Lactate). Cairo: Dar Al-Fikr Al-Arabi; 2000. 206 p.
4. Fadel K., M. An Introduction to Physiology in Athletic Training, Baghdad: Al-Shuwaili Press; 2008. 84-85 p.

5. Ibrahim Salem Al-Sakkar, et al. Physiology Encyclopedia of Track Competitions, 1st edition, Cairo: The Book Publishing Center; 1998. 133 p.

6. Al-Kaabi J. Physiological and Chemical Foundations of Sports Training,. Doha: Qatar National Press; 2007. 225 p.

7. James E. Turner*, Jos A. Bosch and SarahAldred. Measurement of exercise-induced oxidative stress in lymphocytes, Clinical Immunology, School of Immunity and Infection, Birmingham: College of Medical and Dental Sciences, University of Birmingham; 2011.

8. Hussein Ahmed Heshmat and Nader Muhammad Shalaby. Physiology of Muscular Fatigue, First Edition, Cairo: The Book Center for Publishing; 2003. 135 p.

9. Nasr Radwan M. Method of Measuring Physical Exercise in Sports. 4th ed. Cairo: The Book Publishing Center; 1998. 208 p.

10. Hussain Al-Bishtawi M, Mahmoud Ismail A. Physical Training Physiology. 1st ed. Wael House for Publishing and Distribution; 2006. 296 p.

11. Suleiman R, Malik Al-Rawi A. Principles of Modern Biochemistry. 1st ed. Baghdad: Higher Education Press; 1988. 182 p.

12. Hussein Q. Physiology - its principles and application in the sports field. Mosul: Dar AlHekma for Printing and Publishing; 1990. 146 p.

13. Al-Merab S. Chemistry and Sports. Baghdad: Dar Al-Kitab for Printing and Publishing, B.T; 1987. 58-59 p.

14. Khalil Muhammad S. Principles of Mathematical Physiology. 1st ed. Nass Printing Company; 2008. 390-391 p. 